\title{
ANALISA BEBAN KERJA MENTAL DAN FISIK OPERATOR HD KOMATSU 785-7 (STUDI KASUS PT.SIMS JAYA KALTIM)
}

\author{
Hotma Kristian Silalahi* \\ Program Studi Teknik Industri, Universitas Mulawarman, Kota Samarinda, Indonesia \\ Lina Dianati Fathimahhayati \\ Program Studi Teknik Industri, Universitas Mulawarman, Kota Samarinda, Indonesia \\ Willy Tambunan \\ Program Studi Teknik Industri, Universitas Mulawarman, Kota Samarinda, Indonesia \\ *E-mail korespondensi:kristianhotma@gmail.com.
}

\begin{abstract}
ABSTRAK
PT. Sims Jaya Kaltim merupakan salah satu perusahaan terkemuka dibidang kontraktor penyedia jasa pertambangan yang berfokus pada pengangkutan material Overburden (OB). Operator HD Komatsu 785-7 bertugas untuk mengangkut material dari disposal menuju ke dumpingan. Pengukuran beban kerja fisik menggunakan metode pengukuran \%CVL (cardiovasculair load) selama 6 hari dengan pengukuran denyut jantung pada saat bekerja dan istirahat menggunakan alat pulse oxymeter lalu dihitung menggunakan rumus \%CVL. Pengukuran beban kerja mental menggunakan metode NASA-Task Load Index dengan membagikan kuesioner kepada 30 operator HD Komatsu 785-7. Pengukuran dilakukan selama 6 hari kerja. Pengukuran dibagi menjadi 3 regu, satu regu terdiri dari 10 operator. Berdasarkan hasil pengukuran yang telah dilakukan didapatkan nilai rata-rata \%CVL dengan rata-rata keseluruhan 17,00\% yang berarti operator tidak mengalami kelelahan fisik karena $<30 \%$ termasuk dalam kategori ringan. Hasil beban dengan rata-rata keseseluruhan sebesar 66,60 yang termasuk dalam golongan perkrjaan tinggi (61-80) yang berarti memerlukan perhatian khusus. Rekomendasi Usulan perbaikan yang diberikan kegiatan random fatique, kontroling pengisian $\mathrm{KKH}$, kontroling jalan, dan kontroling debu.
\end{abstract}

Kata Kunci: Operator HD Komatsu 785-7, \%CVL, NASA- Task Load Index

\begin{abstract}
PT. Sims Jaya Kaltim is one of the leading companies in the mining service contracting sector that focuses on the transportation of Overburden (OB) material. HD Komatsu 785-7 operator is in charge of transporting material from disposal to dumping. Measurement of physical workload using the\% CVL (cardiovascular load) measurement method for 6 days by measuring heart rate at work and at rest using a pulse oxymeter then calculated using the\% CVL formula. Measurement of mental workload using the NASA-Task Load Index method by distributing questionnaires to 30 operators of HD Komatsu 785-7. Measurements were taken for 6 working days. The measurement is divided into 3 teams, one team consists of 10 operators. Based on the results of the measurements that have been made, the mean value of\% CVL with an overall average of $17.00 \%$ means that the operator does not experience physical fatigue because $<30 \%$ is included in the mild category. The resulting load with an overall average of 66.60 which is included in the high work class (61-80) which means it requires special attention. Recommendations Recommendations for repairs are given by random activities, controlling the filling of the KKH, controlling roads, and controlling dust.
\end{abstract}

Keywords: HD Komatsu 785-7 Operators, \%CVL, NASA-Task Load Index. 


\section{PENDAHULUAN}

Aktivitas manusia yang melebihi kemampuannya dapat menyebabkankelelahan fisik danmental sehingga mengakibatkan terjadinya kecelakaan kerja dan penurunan kinerja. Kemampuan pekerja dapat diketahui dengan melakukan pengukuran beban kerja. Menurut Farihah dan Annisa (2017), beban kerja dapat didefinisikan sebagai suatu perbedaan antara kapasitas atau kemampuan pekerjaan dengan tuntuntan pekerjaan yang harus dihadapi. Pengukuran beban kerja terbagi atas dua yaitu beban kerja fisik dan beban kerja mental. Secara umum beban kerja mental tidak memiliki dampak yang terlihat secara langsung. Pekerja cenderung tidak menyadari bahwa beban kerjanya berlebih. Sedangkan beban kerja fisik memilki dampak yang terlihat secara langsung seperti penurunan kinerja dan kesalahankesalahan yang dilakukan oleh pekerja. Menurut Birana, et al. (2019), beban kerja yang berlebih dapat menyebabkan kelelahan kerja. Kelelahan kerja merupakan salah satu permasalahan kesehatan dan keselamatan kerja yang dapat menjadi faktor risiko terjadinya kecelakaan pada saat bekerja.

Berdasarkan data Direktorat Jenderal Mineral Dan Batubara 2019, kecelakaan kerja pada perusahaan tambang $85 \%$ terjadi pada perusahaan kontraktor. Salah satu perusahaan kontraktor yang ada di Kalimantan Timur adalah PT. Sims Jaya Kaltim bergerak pada bidang pertambangan batu bara yang beroperasi selama 19 tahun. Penelitian ini akan membahas menegenai beban kerja mental dan fisik Operator HD Komatsu 785-7.

Operator merupakan seorang yang bertugas untuk mengoperasikan alat di suatu perusahaan. Salah satu operator yang memiliki tingkat resiko yang tinggi adalah operator HD Komatsu 785-7 karena memiliki ukuran kendaraan yang besar sehingga jika operator melakukan kesalahan dapat menyebabkan kecelakaan dapat berakibat fatal. Operator HD yang bertugas untuk mengakut material Overburden (OB) dalam proses penambangan batu bara. Operator tersebut dituntut untuk selalu fokus dalam bekerja dan selalu melakukan komunikasi agar tidak terjadi kecelakaan kerja. Beban kerja mentalyang dialami operator adalah kejenuhan karena operator HD Komatsu 785-7 harus duduk selama 9 (Sembilan) jam serta melakukan kegiatan pengangkutan material OB dari front loading menuju disposal secara secara berulang. Sedangkan beban fisik yang dialami operator, diantaranya duduk dalam waktu yang lama dapat menyebabkan nyeri punggung. Menurut Birana, dkk. (2019), Kelelahan pengemudi merupakan salah satu faktor resiko kecelakaan dalam transportasi. Kelelahan pengemudi menimbulkan menurunnya daya konsentrasi, timbulnya rasa kantuk, lambatnya bereaksi, kelelahan pada mata kejenuhan, penurunan perhatian, tertidur sesaat, dan keluar dari jalur yang seharusnya. Karena hal ini Penelitian pengkuran beban kerja mental dan fisik operator HD Komatsu785-7 penting untuk dilakukan.

Metode yang digunakan pada penelitian ini yaitu metode NASA TLX dan \%CVL. NASATLX (Task Load Index) adalah pengukuran yang dibagi atas enam dimensi.Penentuan pengukuran beban kerja mental meliputi kebutuhan fisik, kebutuhan mental, tekanan, waktu pencapaian kinerja usaha dan tingkat stress. NASA TLX dibagi atas dua bagian yaitu tahap perbandingan skala dan pemberian nilai terhadap pekerjaan. Metode NASA-TLX memiliki kelebihan diantaranya cocok untuk berbagai jenis pekerjaan dan setiap faktor penilaian mampu memberikan informasi mengenai beban kerja yang dialami.Selanjutnyapengukuran beban kerja fisik dilakukan dengan menggunakan metode \%CVL. Metode \%CVL dilakukan dengan melakukan pengukuran denyut nadi pekerja. Kelebihan metode \%CVL adalah nilai beban fisik dapat diketahui denyut jantung kerja dari operator. Kemudian dari hasil perhitungan tersebut akan dirumuskan usulan perbaikan untuk mengatasi beban kerja mental dan fisik yang terjadi pada operator HD Komatsu 785-7 PT. Sims Jaya Kaltim.

\section{BAHAN DAN METODE}

Metode penelitian ini dilakukan dengan pendekatan kuantitatif. Dengan menggunakan mentode NASA-Task Load Index untuk mengukur beban kerja mental.dan metode \%CVL untuk mengukur beban kerja fisik. Penelitian ini dilakukan pada PT. Sims Jaya Kaltim kepada 30 operator HD Komatsu 785-7. Teknik pengumpulan data yang digunakan pada penelitian ini 
adalah tahap observasi, studi pustaka, kuesioner, dan pengukuran langsung.Data primer merupakan data yang didapatkan peneliti secara langsung. Data primer pada penelitian ini terdiri dari data nilai bobot dan beban kerja mental yang terdapat pada operator HD Komatsu 785-7 yang diolah menggunakan metode NASA-TLX dan Melakukan pengukuran denyut jantung operator HD Komatsu 785-7 yang didapatkan peneliti berdasarkan pengukuran langsung menggunakan alat fingertips pulse oximeter kemudian dihitung dengan \%CVL. Sedangkan data sekunder merupakan data yang didapatkan secara tidak langsung melalui media perantara, data sekunder tersebut diperoleh berdasarkan dokumen perusahaan ataupun melalui website resmi milik perusahaan.

\section{a. Beban Kerja}

Beban kerja dapat didefinisikan sebagai suatu perbedaan antara kapasitas atau kemampuan pekerjaan dengan tuntutan pekerjaan yang harus dihadapi. Mengingat kerja manusia bersifat mental dan fisik, maka masing-masing mempunyai tingkat pembebanan yang berbeda-beda. Tingkat pembebanan yang terlalu tinggi memungkinkan pemakaian energi yang berlebihan dan overstress, sebaliknya intensitas pembebanan yang terlalu rendah meungkinkan rasa bosan dan kejenuhan atau understress (Farihah dan Annisa, 2017).

\section{b. Beban Kerja Mental}

Menurut Puteri dan Sukarna (2017), Beban kerja mental yang merupakan perbedaan antara tuntutan kerja mental dengan kemampuan mental yang dimiliki oleh pekerja yang bersangkutan. Beban kerja yang timbul dari aktivitas mental di lingkungan kerja antara lain disebabkan oleh :

1). Keharusan untuk tetap dalam kondisi kewaspadaan tinggi dalam waktu lama

2). Kebutuhan untuk mengambil keputusan yang melibatkan tanggung jawab besar

3). Menurunnya konsentrasi akibat aktivitasyang monoton

4). Kurangnya kontak dengan orang lain, terutama untuk tempat kerja yang terisolasi dengan orang lain.

\section{c. Beban Kerja Fisik}

Beban kerja fisik adalah beban Perkerjaan yang di terima oleh fisik pekerja yang dilakukan dengan mengandalkan kegiatan fisik semata akan mengakibatkan perubahan pada fungsi alatalat tubuh. Beban kerja fisik menjadikan konsumsi energisebagai factor utama yang dijadikan tolak ukur penentu berat atau ringannya suatu pekerjaan (Purwaningsih, 2017).

\section{d. NASA-Task Load Index}

Menurut Amri (2017), langkah-langkah dalam pengukuran beban kerja mental dengan menggunakan metode NASA-TLX, yaitu:

1). Penjelasan Indikator Beban Mental yang Akan Diukur Indikator

Tabel 1. Indikator Beban Mental

\begin{tabular}{|c|c|c|c|}
\hline No & Dimensi & Deskripsi & Skala Rating \\
\hline 1 & $\begin{array}{l}\text { Tuntutan Mental } \\
\text { (Mental Demand) }\end{array}$ & $\begin{array}{l}\text { Seberapa besar tututan aktivitas mental yang dibutuhkan dalam } \\
\text { pekerjaan (contoh: berpikir, menghitung, mengingat, melihat) } \\
\text { Apakah pekerjaan tersebut mudah atau sulit, sederhana atau } \\
\text { kompleks, longgar atau ketat? }\end{array}$ & Rendah-Tinggi \\
\hline 2 & $\begin{array}{l}\text { Kebutuhan Fisik } \\
\text { (Physical demand) }\end{array}$ & $\begin{array}{l}\text { Jumlah aktifitas fisik yang dibutuhkan operator (misalnya: } \\
\text { mendorong, menarik dan mengontrol putaran) }\end{array}$ & Rendah-Tinggi \\
\hline 3 & $\begin{array}{l}\text { Tuntutan Waktu } \\
\text { (Temporary } \\
\text { Demand) }\end{array}$ & $\begin{array}{l}\text { Seberapa besar tekanan waktu yang dirasakan selama pekerjaan } \\
\text { atau elemen pekerjaan berlangsung? Apakah pekerjaan perlahan } \\
\text { dan santai, atau cepat dan melelahkan? }\end{array}$ & Rendah-Tinggi \\
\hline 4 & $\begin{array}{l}\text { Performansi } \\
\text { (Own Performance) }\end{array}$ & $\begin{array}{l}\text { Seberapa besar keberhasilan di dalam mencapai target pekerjaan? } \\
\text { Seberapa puas performansi di dalam mencapai target tersebut? }\end{array}$ & Rendah -Tinggi \\
\hline 5 & $\begin{array}{l}\text { Tingkat Usaha } \\
\text { (Effort) }\end{array}$ & $\begin{array}{l}\text { Seberapa besar usaha yang dikeluarkan secara mental dan fisik } \\
\text { yang dibutuhkan untuk mencapai level performansi }\end{array}$ & Rendah-Tinggi \\
\hline 6 & $\begin{array}{l}\text { Tingkat Frustasi } \\
\text { (Frustation) }\end{array}$ & $\begin{array}{l}\text { Seberapa besar usaha yang dikeluarkan secara mental dan fisik } \\
\text { yang dibutuhkan untuk mencapai level performansi }\end{array}$ & Rendah-Tinggi \\
\hline
\end{tabular}


2). Pembobotan

Pada bagian ini responden diminta untuk memilih salah satu dari dua indikator yang dirasakan lebih dominan menimbulkan beban kerja mental terhadap pekerjaan tersebut. Kuisioner NASA-TLX yang diberikan berbentuk perbandingan berpasangan yang terdiri dari 15 perbandingan berpasangan. Dari kuisioner ini dihitung jumlah tally dari setiap indikator yang dirasakan paling berpengaruh. Jumlah tally ini kemudian akan menjadi bobot untuk tiap indikator beban mental. Indikator perbandingan 15 berpasangan dapat dilihat pada Tabel 2.

Tabel 2. Perbandingan Berpasangan NASA-TLX

\begin{tabular}{lll}
\hline No & \multicolumn{2}{c}{ Perbandingan Berpasangan } \\
\hline 1 & Tingkat Usaha (TU) & Performance (P) \\
2 & Kebutuhan Waktu (KW) & Tingkat Frustasi (TF) \\
3 & Kebutuhan Waktu (KW) & Tingkat Usaha (TU) \\
4 & Kebutuhan Fisik (KF) & Tingkat Frustasi (TF) \\
5 & Performance (P) & Tingkat Frustasi (TF) \\
6 & Kebutuhan Fisik (KF) & Kebutuhan Waktu (KW) \\
7 & Kebutuhan Fisik (KF) & Performance (P) \\
8 & Kebutuhan Waktu (KW) & Kebutuhan Mental (KM) \\
9 & Tingkat Frustasi (TF) & Tingkat Usaha (TU) \\
10 & Performance (P) & Kebutuhan Mental (KM) \\
11 & Performance (P) & Kebutuhan Waktu (KW) \\
12 & Kebutuhan Mental (KM) & Tingkat Usaha (TU) \\
13 & Kebutuhan Mental (KM) & Kebutuhan Fisik (KF) \\
14 & Tingkat Usaha (TU) & Kebutuhan Fisik (KF) \\
15 & Tingkat Frustasi (TF) & Kebutuhan Mental (KM) \\
\hline
\end{tabular}

3). Pemberian Rating

Pada bagian ini responden diminta memberi rating terhadap keenam indikator beban mental. Rating yang diberikan adalah subjektif tergantung pada beban mental yang dirasakan oleh responden tersebut. Rating yang diberikan adalah subjektif tergantung pada beban mental yang dirasakan oleh responden tersebut. Untuk mendapatkan skor beban mental NASA-TLX, bobot dan rating untuk setiap indikator dikalikan kemudian dijumlahkan dan dibagi 15 (jumlah perbandingan berpasangan). Berdasarkan skala Rating Sheet pada metode NASA-TLX mengunakan skala dari 0 sampai 100 , nilai 0 berada pada range rendah (low) dan nilai 100 berada pada range tinggi (high). Kategori ini digunakan sebagai nilai pengali pada bobot yang diambil dari hasil wawancara berikut merupakan contoh rating sheet Gambar 1.

Menurut Diniaty dan Ikhsan (2018), penjabaran yang didapat pada metode NASA-TLX berikut ini merupakan langkah mengolah data yang dapat dijelaskan sebagai berikut:

1). Menghitung Produk

Produk diperoleh dengan cara mengalikan rating dengan faktor untuk masing-masing deskriptor. Dengan demikian dihasilkan 6 nilai produk untuk 6 indikator (KM, KW, KF, P, TU, dan TF)

Produk $=$ Rating $\times$ Bobot kerja

2). Menghitung Weighted Workload (WWL)

WWL diperoleh dengan cara menjumlahkan keenam nilai produk

$\mathrm{WWL}=\sum$ produk

3). Menghitung Rata-rata WWL

Rata-rata WWL diperoleh dengan cara membagi WWL dengan bobot total.

$$
\text { Skor }=\frac{\sum(\text { bobot } \times \text { rating })}{15}
$$




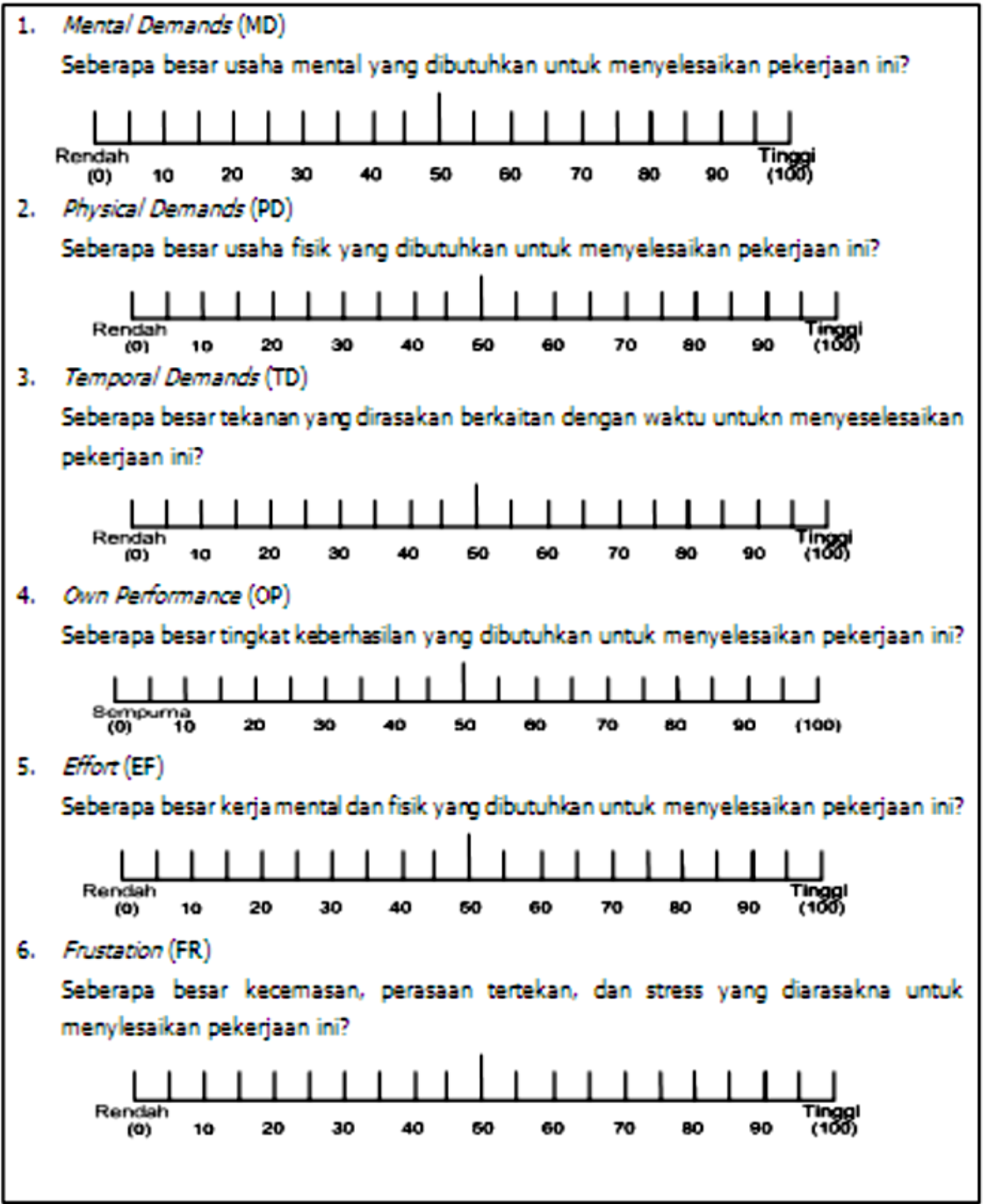

Gambar 1. Rating Sheet NASA-TLX

4). Interpretasi Nilai Skor

Berdasarkan pengkategorian dalam teori Nasa-TLX kategori beban kerja mental diklarifikasikan menjadi lima indikator sebagai berikut:

- Golongan pekerjaan sangat rendah (0-20)

- Golongan pekerjaan rendah (21-40)

- Golongan pekerjaan sedang (41-60)

- Golongan pekerjaan tinggi (61-80)

- Golongan pekerjaan sangat tinggi (81-100)

e. Metode \%CVL

\%CVL merupakan metode yang digunakan untuk mengukur beban kerja fisik dengan melakukan pengukuran denyut jantung. Menurut Puteri dan Sukarna (2017), berat ringannya beban kerja yang diterima oleh seorang tenaga kerja dapat digunakan untuk menentukan berapa lama seorang tenaga kerja dapat melakukan aktivitas kerjanya sesuai dengan kemampuan atau kapasitas kerja yang bersangkutan. Di mana semakin berat beban kerja, maka akan semakin pendek waktu seseorang untuk bekerja tanpa kelelahan dan gangguan fisiologis yang berarti atau sebaliknya. Sebaliknya, bila beban kerja yang diberikan terlalu ringan maka akan menimbulkan kebosanan pada seseorang atau operator. Kebutuhan utama dalam pergerakkan otot adalah kebutuhan akan oksigen yang dibawa oleh darah ke otot untuk pembakaran zat 
dalam menghasilkan energi. Sehingga jumlah oksigen yang dipergunakan oleh tubuh merupakan salah satu indikator pembebanan selama bekerja. Dengan demikian setiap aktivitas pekerjaan memerlukan energi yang dihasilkan dari proses pembakaran. Berdasarkan hal tersebut maka kebutuhan kalori dapat digunakan sebagai indikator untuk menentukan besar ringannya beban kerja.

1). Beban kerja ringan : 100-200 Kilo kalori/ jam

2). Beban kerja sedang: $>200-350$ Kilo kalori/ jam

3). Beban kerja berat : $>350-500$ Kilo kalori/ jam

Menurut Puteri dan Sukarna (2017), salah satu yang dapat digunakan untuk menghitung denyut jantung adalah telemetri dengan menggunakan rangsangan Electrocardio Graph (ECG). Apabila peralatan tersebut tidak tersedia dapat memakai stopwatch dengan metode 10 denyut. Dengan metode tersebut dapat dihitung denyut nadi kerja sebagai berikut:

Denyut nadi $=\frac{10 \text { denyut }}{\text { waktu perhitungan }} \times 60$

Menurut Puteri dan Sukarna (2017), selain metode denyut jantung tersebut, dapat juga dilakukan penghitungan denyut nadi dengan menggunakan metode 15 atau 30 detik. Penggunaan nadi kerja untuk menilai berat ringanya beban kerja memiliki beberapa keuntungan. Beberapa keuntungan penggunaan nadi adalah tidak menggangu aktivitas pekerja yang diukur, selain mudah, cepat, dan murah. Kepekaan denyut nadi akan segera berubah dengan perubahan pembebanan, baik yang berasal dari pembebanan mekanik, fisika, maupun kimiawi. Denyut nadi untuk mengestimasi index beban kerja terdiri dari beberapa jenis,yaitu:

1). Denyut jantung pada saat istirahat (resting pulse) adalah rata-rata denyut jantung sebelum suatu pekerjaan dimulai.

2). Denyut jantung selama bekerja (working pulse) adalah rata-rata denyut jantung pada saat seseorang bekerja.

3). Denyut jantung untuk bekerja (work pulse) adalah selisih antara denyut jantung selama bekerja dan selama istirahat.

4). Denyut jantung selama istirahat total (recovery cost or recovery cost) adalah jumlah aljabar denyut jantung dan berhentinya denyut pada suatu pekerjaan selesai dikerjakannya sampai dengan denyut berada pada kondisi istirahatnya.

5). Denyut kerja total (Total work pulse or cardiac cost) adalah jumlah denyut jantung dari mulainya suatu pekerjaan sampai dengan denyut berada pada kondisi istirahatnya (resting level). Lebih lanjut untuk menentukan klasifikasi beban kerja berdasakan peningkatan denyut nadi kerja yang dibandingkan dengan denyut nadi maskimum karena beban kardiovaskuler (cardiovascular $=\% C V L$ ) yang dihitung berdasarkan rumus di bawah ini:

$\% \mathrm{CVL}=\frac{\text { DNK-DNI }}{\text { DNMaks-DNI }} \times 100$

Menurut Puteri dan Sukarna (2017), denyut nadi maskimum adalah (220-umur) untuk lakilaki dan (200-umur) untuk wanita. Dari perhitungan \% CVL kemudian akan dibandingkan dengan klasifikasi yang telah ditetapkan sebagai berikut:

1). $<30 \%=$ Tidak terjadi kelelahan

2). $30-<60 \%=$ Diperlukan perbaikan

3). $60-<80=$ Kerja dalam waktu singkat

4). $80-<100 \%=$ Diperlukan tindakan segera

5). $>100 \%=$ Tidak diperbolehkan beraktivitas.

Berdasarkan beberapa interpretasi nilai skor tersebut klasifikasi yang dilakukan terhadap beban kerja mental dapat lebih mudah dan sederhana. Nilai skor ini merupakan nilai akhir yang digunakan untuk menganalisa ke tahap selanjutnya.

\section{HASIL DAN PEMBAHASAN}

\section{a. Beban Kerja Mental}

Pengukuran beban kerja mental yang dilakukan oleh peneliti berfungsi untuk mengetahui seberapa besar beban mental yang dialami oleh operator HD Komatsu 785-7 selama 
mengoperasikan unit. Pengukuran beban kerja mental dilakukan selama sekali dalam sehari dengan memberikan kuesioner kepada operator pada waktu istirahat. Pengukuran beban kerja mental dilakukan dengan melakukan penyebaran kuesioner kepada operator HD Komatsu 7857.

Pengukuran beban kerja mental ini dilakukan dengan cara memberikan kuesioner kepada 30 operator. Berdasarkan data yang telah didapatkan, maka dilakukan langkah lanjuntan untuk mengetahui beban kerja mental operator HD Komatsu 785-7 pada Regu A, Regu B dan Regu C. Adapun perhitungan beban kerja mental Regu A, Regu B, dan Regu C operator HD Komatsu 785-7 dapat dilihat pada Gambar 3, Gambar 4, dan Gambar 5.

Berdasarkan Gambar 2, dapat diketahui rata-rata beban kerja mental yang dialami operator Hd Komatsu 785-7 pada Regu A. Menurut operator peningkatan beban mental dipengaruhi oleh faktor cuaca karena pada saat cuaca panas operator harus bekerja secara terus menerus yang dapat menyebabkan kejenuhan meningkat karena operator harus duduk selama 9 jam diunitnya sedangkan pada cuaca hujan operator tidak melakukan aktivitas pengangkutan. Pada saat hujan operator dapat memanfaatkan waktunya dengan tidur dikabin atau beristirahat di kontainer yang ada di pit stop. Hal yang mempengaruhi Regu A mengalami perbedaan golongan dengan regu lainnya adalah kondisi jalan geometri jalan yang dilewati tergolong baik. Kondisi jalan geometri jalan yang baik menjadi faktor pendukung karena dengan kondisi geometri jalan yang baik membuat operator lebih nyaman dalam mengemudikan unitnya dan tidak terkendala dalam proses pengangkutan.

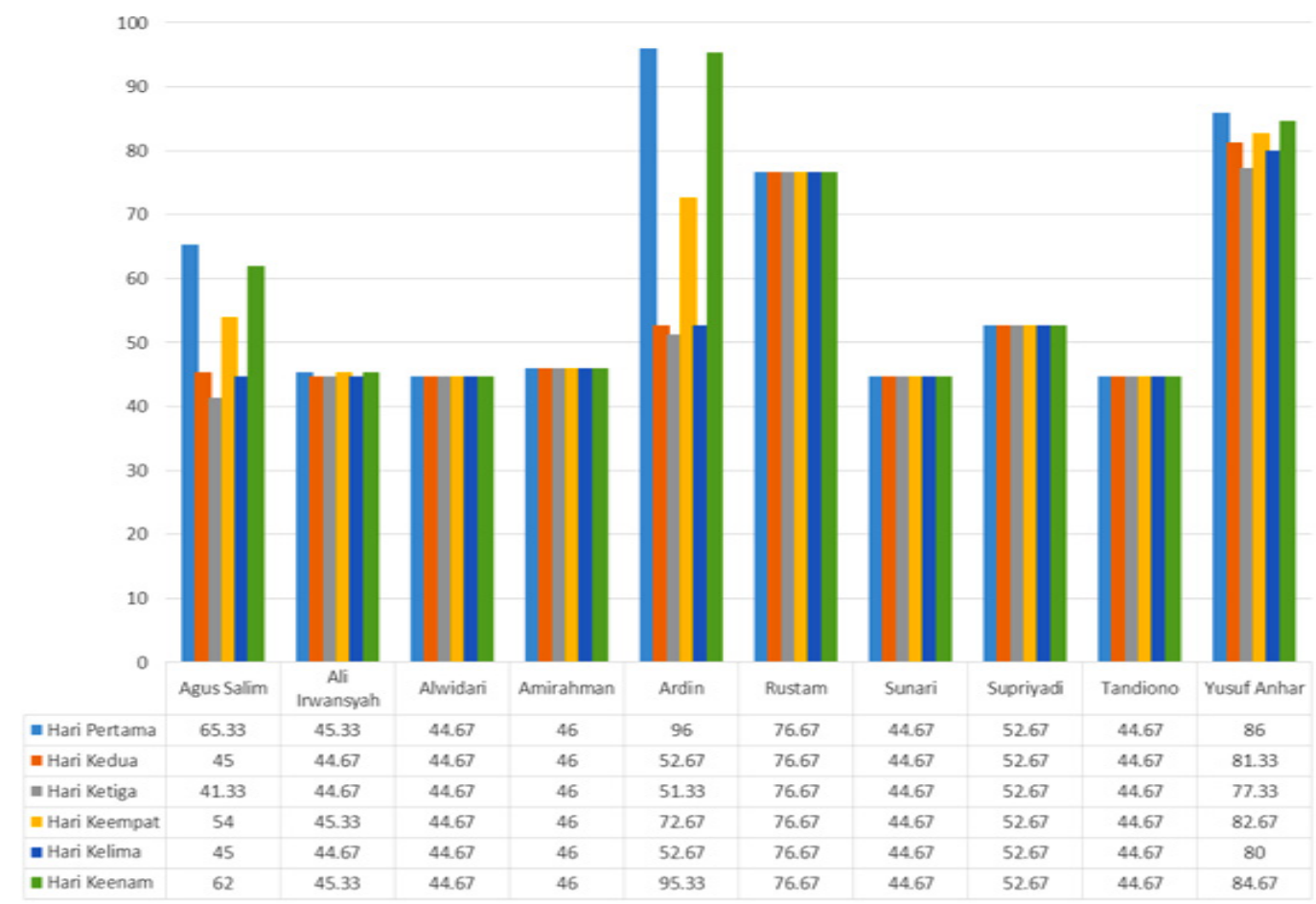

Gambar 2. Beban Kerja Mental Regu A

Berdasarkan Gambar 3 dapat diketahui rata-rata beban kerja fisik yang dialami operator HD Komatsu 785-7pada Regu B. Menurut operator peningkatan beban mental dipengaruhi oleh faktor cuaca karena pada saat cuaca panas operator harus bekerja secara terus menerus yang dapat menyebabkan kejenuhan meningkat karena operator harus duduk selama 9 jam diunitnya sedangkan pada cuaca hujan operator tidak melakukan aktivitas pengangkutan. Pada saat hujan operator dapat memanfaatkan waktunya dengan tidur dikabin atau beristirahat di kontainer yang ada di pit stop. Peningkatan beban mental yang dialami Regu B dikarenakan kondisi geometri jalan yang kurang baik. Sehingga membuat operator menjadi tidak nyaman dalam 
mengemudikan unitnya dengan kondisi geometri jalan yang bergelombang memperlambat operator saat mengoperasikan unit.

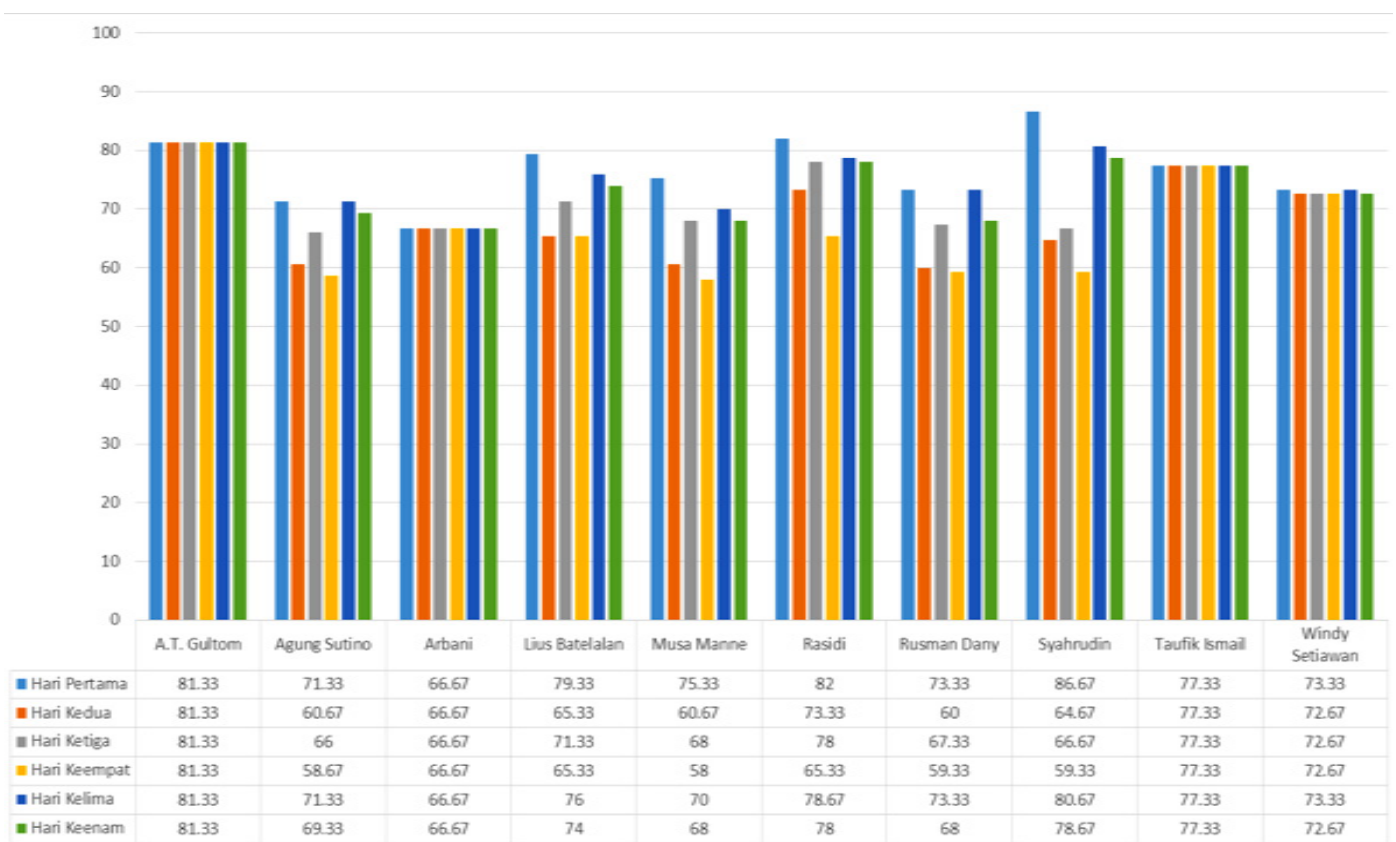

Gambar 3. Beban Kerja Mental Regu B

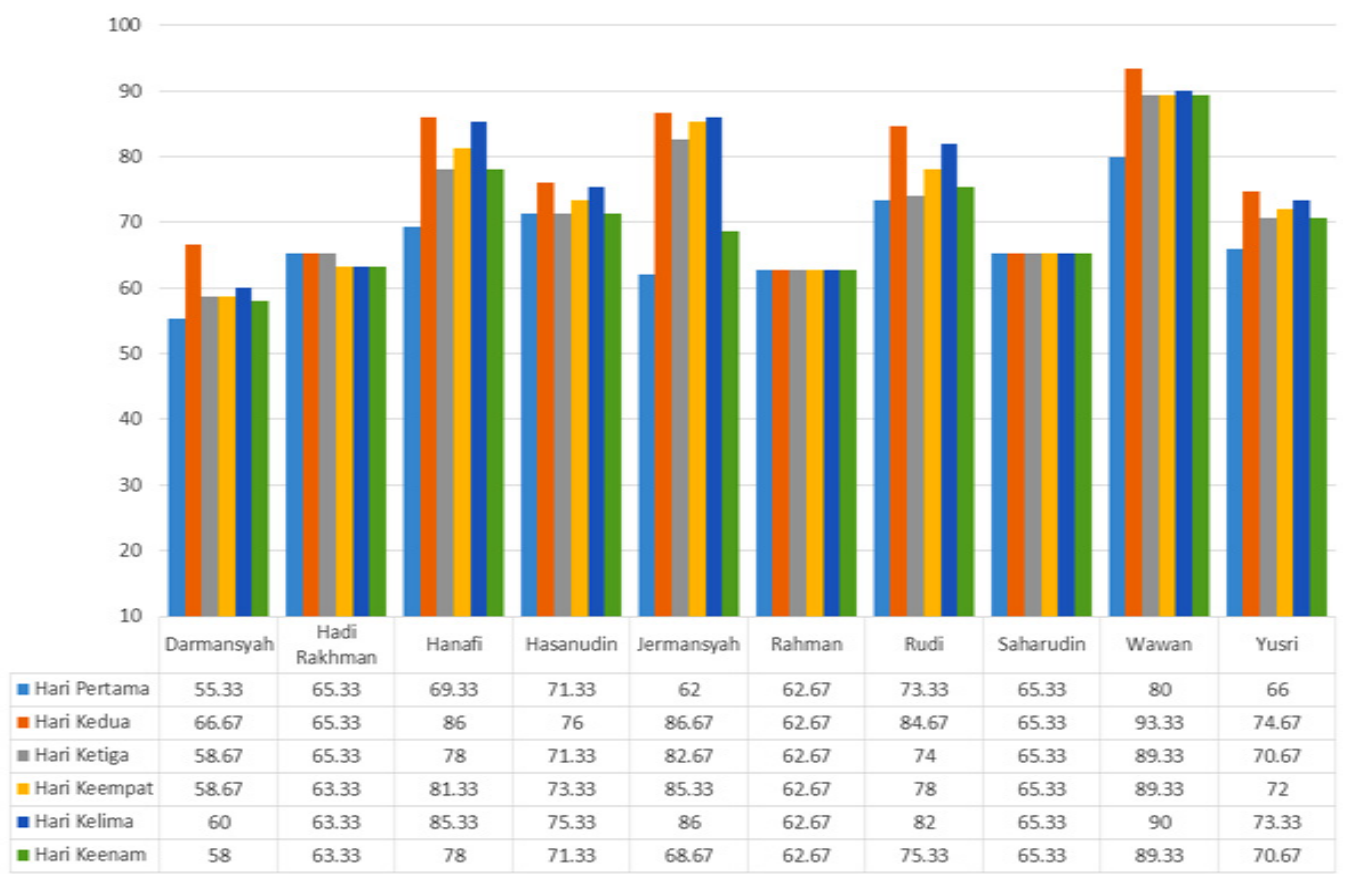

Gambar 4. Beban Kerja Mental C

Berdasarkan Gambar 4, dapat diketahui rata-rata beban kerja fisik yang dialami operator HD Komatsu 785-7 pada Regu C. Menurut operator peningkatan beban mental dipengaruhi oleh faktor cuaca karena pada saat cuaca panas operator harus bekerja secara terus menerus yang dapat menyebabkan kejenuhan meningkat karena operator harus duduk selama 9 jam diunitnya sedangkan pada cuaca hujan operator tidak melakukan aktivitas pengangkutan. Pada saat hujan operator dapat memanfaatkan waktunya dengan tidur dikabin atau beristirahat di kontainer yang ada di pit stop. Peningkatan beban mental yang dialami Regu C dikarenakan 
kondisi geometri jalan yang kurang baik. Sehingga membuat operator menjadi tidak nyaman dalam mengemudikan unitnya dengan kondisi geometri jalan yang bergelombang memperlambat operator saat mengoperasikan unit dan debu yang meningkat yang membuat operator harus menginkatkan fokusnya saat mengoperasikan unit.

\section{b. Analisis Perbandingan Beban Kerja mentalBerdasarkan Regu}

Nilai rata-rata berdasarkan regu adalah pada Regu A sebesar 55,86, Regu B sebesar 71,86 dan Regu C sebesar 72,09 termasuk dalam golongan tinggi karena $>60$. Berdasarkan pembahasan diatas dapat diketahui bahwa sebagian operator menganggap bahwa beban kerja mental yang dialaminya setiap hari sama dan sebagian lagi menganggap bahwa beban kerja yang dialami tergantung pada cuaca. Dari hasil pengukuran beban mental yang telah dilakukan dapat diketahui geometri jalan dan debu berpengaruh terhadap beban mental yang dilalami operator.Nilai perbandingan dapat dilihat pada Gambar 5.

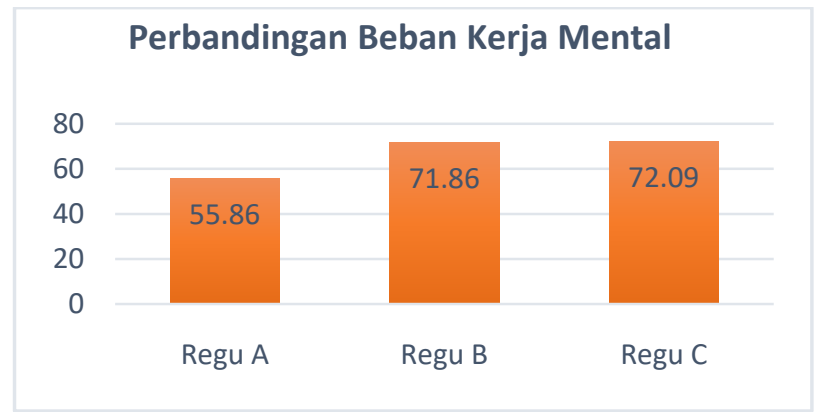

Gambar 5. Perbandingan Beban Kerja Mental

\section{c. Analisis Hasil Pengukuran Beban Kerja Mental Keseluruhan}

Berdasarkan hasil perhitungan yang telah dilakukan didapatkan hasil beban kerja mentalrata-rata sebesar 66.60 termasuk dalam golongan tinggi karena berada pada rentang 61 sampai dengan 80 atau karena $>60$. Dari hasil pengukuran beban mental yang telah dilakukan dapat diketahui geometri jalan dan debu berpengaruh terhadap beban mental yang dilalami operator. Hal ini membuat operator harus meningkatkan kewaspadaan agar tidak terjadi kecelakaan.

\section{d. Beban Kerja Fisik}

Pengukuran beban kerja fisik yang dilakukan oleh peneliti berfungsi untuk mengetahui seberapa besar beban fisik yang dibutuhkan oleh operator selama mengoperasikan unit. Pengukuran beban kerja fisik ini dilakukan sebanyak 4 Kali dalam sehari kepada operator. Pengukuran pertama dilakukan di center control room (CCR) operator yang merupakan tempat awal untuk pengukuran dikarenakan operator saat pertama datang harus berkumpul untuk absen, penandatanganan buku KKH oleh pengawas dan tempat untuk melakukan P5M ( Penyampaian 5 Menit), pengukuran kedua dilakukan pada saat operator selesai memarkirkan unit sedangkan pengukururan ketiga dilakukan setelah operator telah beristirahat dalam selama \pm 30 menit. Pengukuran kedua dan ketiga dilakukan di pit stop, area dumping, dan area front loading, dan pengukuran keempat dilakukan di area Hot Change Shift (HCS). Pengukuran dilakukan untuk mengukur beban kerja fisik operator sebelum pulang. Pengukuran ini dilakukan saat operator selesai memarkirkanunitnya. Berdasarkan data yang telah didapatkan, maka dilakukan langkah lanjuntan untuk mengetahui beban kerja mental operator HD Komatsu 785-7 pada Regu A, Regu B dan Regu C. Nilai beban kerja fisik dapat dijelaskan sebagai berikut.

Berdasarkan rata-rata beban kerja fisik yang dialami operator HD Komatsu 785-7 pada Regu A (lihat Gambar 6) adalah pada hari pertama 28,57\% yang tergolong dalam kategori ringan dan cuaca dalam keadaan panas, pada hari kedua beban kerja fisik sebesar $15,59 \%$ dengan keaadaan cuaca keadaan berawan atau mendung, pada hari ketiga beban kerja fisik sebesar 9,34\% dengan keaadaan cuaca dalam keadaan hujan dengan intensitas tinggi selama 2 
(dua) jam yang menyebabkan operator tidak beroperasi 4 (empat) jam karena karena tanah licin dan jalan harus di scrub selama 2 (dua) menggunakan bulldozer dan grader agar tidak licin saat dilewati oleh HD. Pada hari keempat 19,14\% dengan keadaan cuaca panas, ada hari kelima beban kerja fisik sebesar 11,91\% dengan keaadaan cuaca dalam hujan dengan intensitas rendah selama 2 (jam) yang menyebabkan operator tidak beroperasi selama 3 jam karena jalan harus di scrub selama 1 (satu) jam menggunakan bulldozer dan grader agar tanah tidak licin saat dilewati HD. Pada hari keenam beban kerja fisik sebesar 27,18\%dengan keaadaan cuaca dalam keaadan panas. Berdasarkan penjelasan diatas dapat diketahui presentase rata-rata tertinggi adalah $28,57 \%$ dan presentase rata-rata terendah adalah $9,34 \%$.

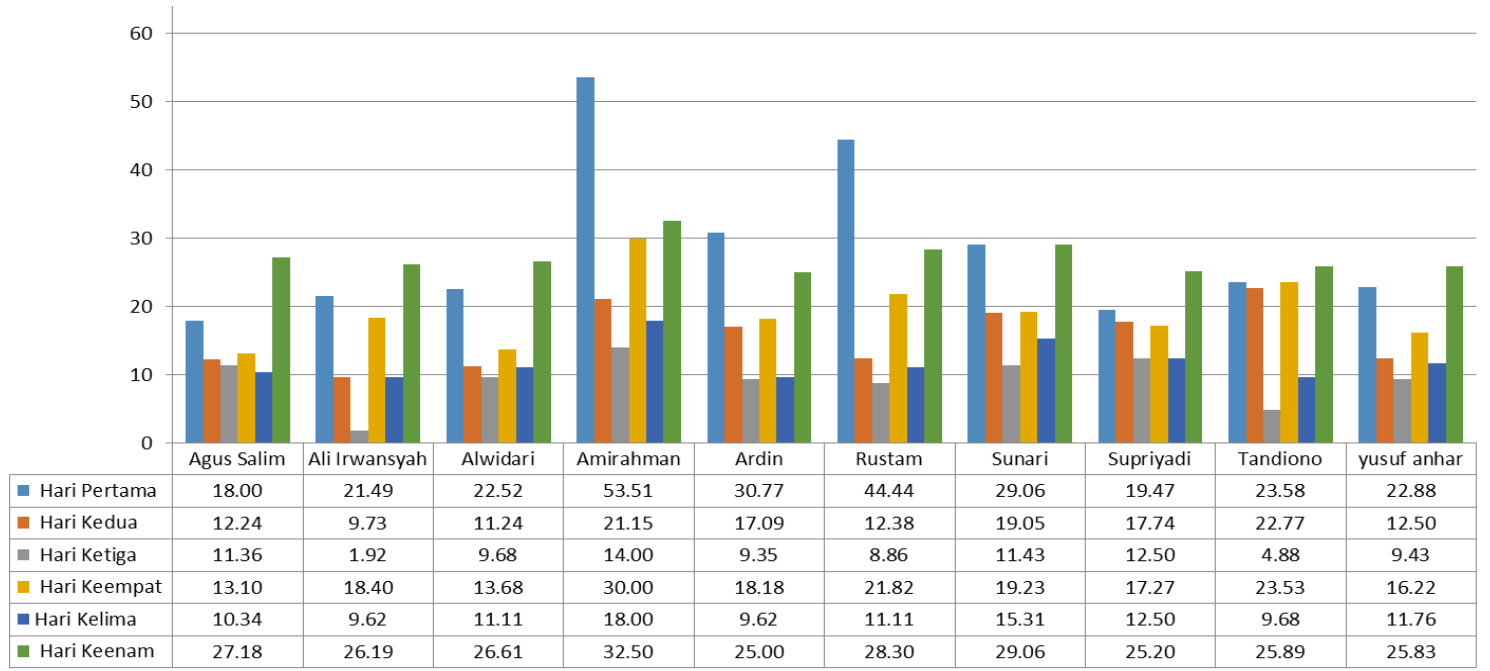

Gambar 6. Beban kerja fisik Regu A

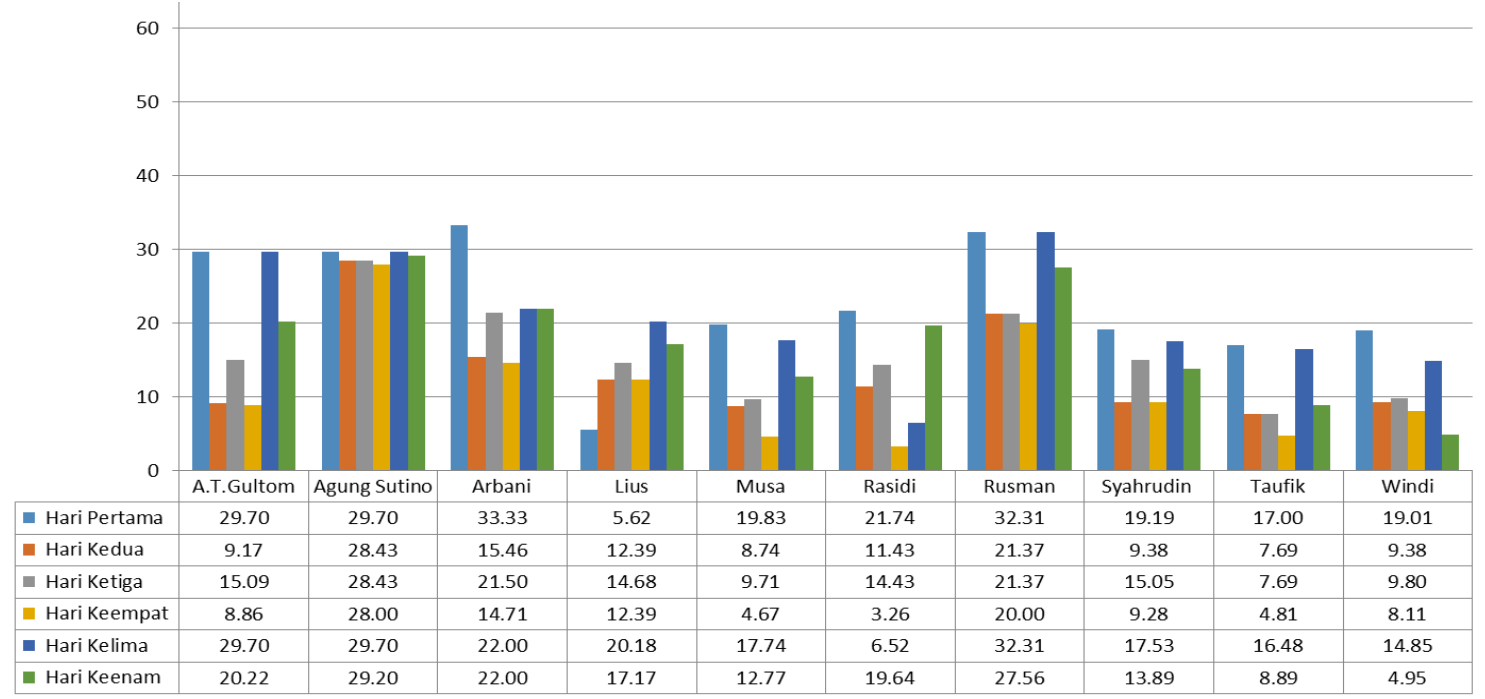

Gambar 7. Beban Kerja Fisik Operator Regu B

Berdasarkan rata-rata beban kerja fisik yang dialami oleh operator HD Komatsu 785-7 Regu B (lihat Gambar 7) adalah pada hari pertama sebesar 22,74\% dengan keaadaan cuaca dalam keadaan panas, pada hari kedua $13,34 \%$ dengan keadaan cuaca dalam keadaan hujan dengan intensitas tinggi selama 1 (satu) jam yang mengakibatkan operator berhenti beroperasi selama 3 (tiga) jam karena jalan harus di scrub selama 2 (dua) jam menggunakan bulldozer dan grader agar tanah tidak licin saat dilewati HD. Pada hari ketiga beban kerja fisik sebebsar $15,78 \%$ dengan keadaan cuaca dalam keaadan panas berawan atau mendung, pada hari keempat beban kerja fisik sebesar $11,41 \%$ dengan keadaan cuaca dalam keadaan hujan dengan intensitas 
rendah selama 2(dua) jam yang menyebabkan operator tidak beroperasi selama 3 (tiga) jam karena jalan harus di scrub selama 1 (satu) jam menggunakan bulldozer dan grader agar tanah tidak licin saat dilewati HD. Pada hari kelima beban kerja fisik sebesar 20,70\%dengan keaadaan cuaca dalam keadaan panas, dan pada hari keenam beban kerja fisik sebesar 17,63\% yang termasuk dengan keadaan dalam keaadan panas. Berdasarkan penjelasan diatas dapat diketahui presentase rata-rata tertinggi adalah $22,74 \%$ dan presentase rata-rata terendah adalah $11,41 \%$.

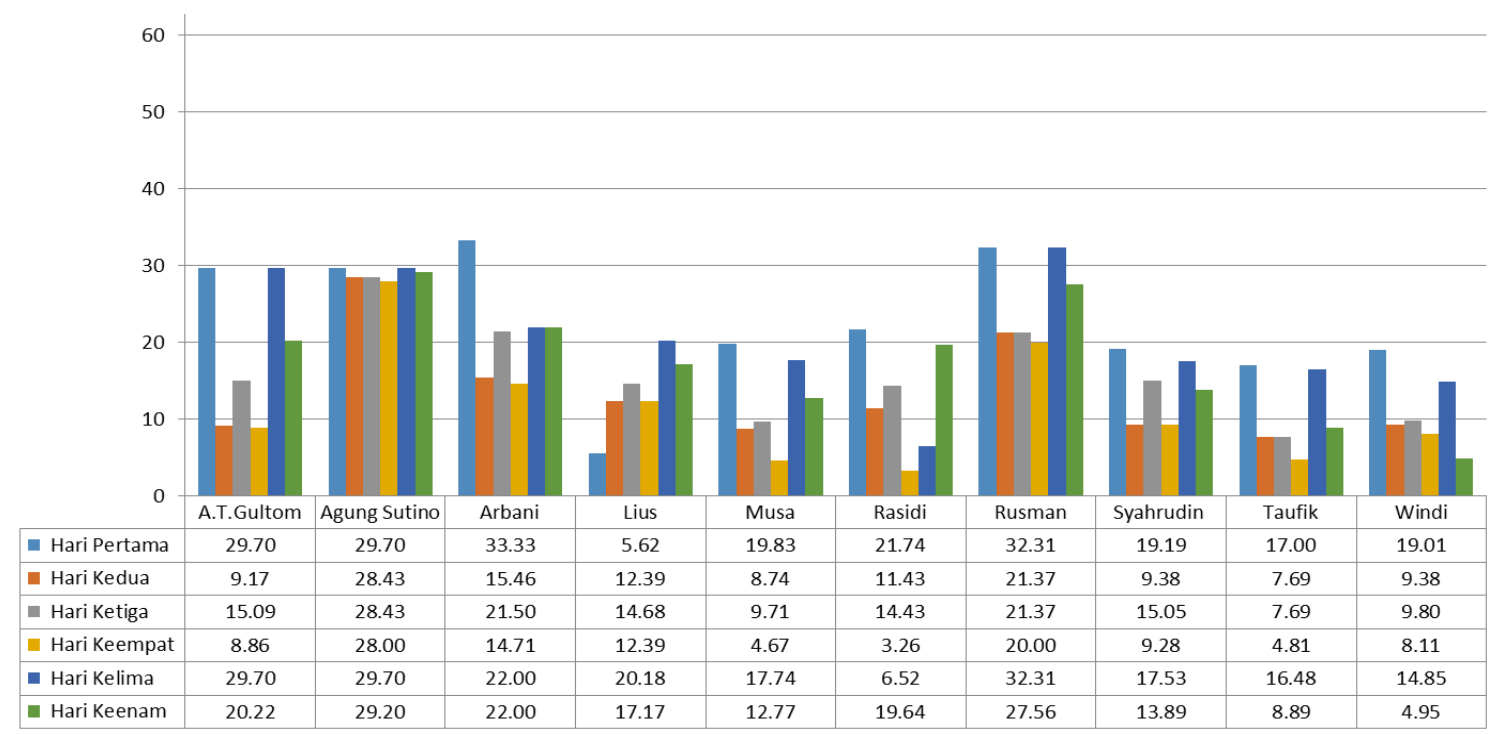

Gambar 8. Beban Kerja Fisik Operator Regu C

Berdasarkan rata-rata beban kerja fisik yang dialami oleh operator HD Komatsu 785-7 Regu C (lihat Gambar 8) adalah pada hari pertama sebesar 7,44\% dengan keadaan cuaca dalam keadaan hujan dengan intesitas tinggi selama 2 (dua) jam yang menyebabkan operator tidak beroperasi selama 4 (empat) jam harus di scrub selama 2 (dua) jam menggunakan bulldozer dan grader agar tidak licin saat dilewati oleh HD. Pada hari kedua beban kerja fisik yang dialami operator $27,81 \%$ dengan keadaan cuaca dalam keadaan panas terik, pada hari ketiga beban kerja fisik sebesar $16,13 \%$ dengan keadaan cuaca dalam keadaan panas berawan atau mendung, pada hari keempat beban kerja fisik sebesar 18,86\% dengan keadaan cuaca dalam keadaan panas, pada hari kelima beban kerja fisik sebesar $23,75 \%$ dengan keadaan cuaca dalam keadaan panas, dan pada hari keenam beban kerja fisik sebesar 11,31\% dengan keadaan cuaca dalam keadaan hujan dengan intensitas rendah selama 2 (dua) jam yang menyebabkan operator tidak beroperasi selama 3 (tiga) jam karena jalan harus di scrub selama 1 (satu) jam menggunakan bulldozer dan grader agar tanah tidak licin saat dilewati HD. Berdasarkan penjelasan diatas dapat diketahui presentase rata-rata tertinggi adalah $27,81 \%$ dan presentase rata-rata terendah adalah $7,44 \%$.

\section{e. Analisis Perbandingan Beban Kerja Fisik Berdasarkan Regu}

Nilai rata-rata berdasarkan regu diilustrasikan pada Gambar 9. Nilai rata-rata pada regu A sebesar 18,62\%, Regu B sebesar 16,93\% dan Regu C sebesar 17,55\% termasuk dalam kategori ringan karena $<30$. Berdasarkan pembahasan di atas, dapat diketahui bahwa cuaca sangat berpengaruh terhadap beban kerja fisik yang dialami oleh operator. Nilai rata-rata semua regu $<30$, maka dapat disimpulkan tidak terjadi kelelahan. Beban kerja fisik tergolong rendah dikarenakan operator bekerja dalam posisi duduk sehingga energi yang dikeluarkan tidak terlalu besar. 


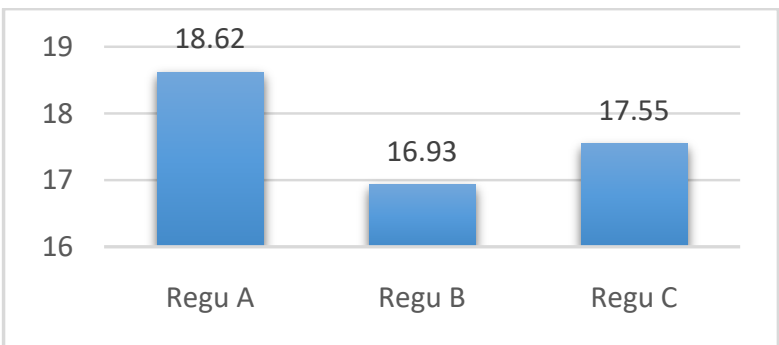

Gambar 9. Perbandingan Beban Kerja Fisik Berdasarkan Regu

\section{f. Analisis Beban Kerja Fisik Secara Keseluruhan}

Berdasarkan Gambar 9 dapat diketahui bahwa rata-rata beban kerja fisik yang dialami operator termasuk dalam kategori ringan dengan rata-rata sebesar $17.70 \%$ dengan 9 orang. Regu A terdiri dari 3 orang yaitu Amirahman sebesar 53, 51\% pada hari pertama, 30\% pada hari keempat dan pada 32,20\% hari keenam, dan Ardin sebesar 30,37\% pada hari pertama pada dan Rustam sebesar 44,44\% pada hari pertama. Regu B yaitu terdiri dari 2 orang Arbani sebesar $33,33 \%$ pada hari pertama,Rusman 32,31\% dan 32,31\% pada hari kelima. Regu C terdiri dari 4 orang yaitu Darmansyah 30\%, Hanafi 30,39\%, Hasanudin 31,48\% dan Rahman 31,73\%. Dari hasil pengukuran beban fisik yang telah dilakukan dapat diketahui geometri jalan dan debu berpengaruh terhadap beban beban fisik yang dilalami operator.

\section{g. Perbaikan dan Usulan}

Perbaikan dan usulan diperlukan agar kedepannya beban kerja yang dialami oleh operator dapat diatasi. Adapun usulan dan perbaikan dari penelitian ini adalah sebagai berikut:

1). Kegiatan Random Fatique

Kegiatan random fatique dilakukan untuk mengecek kondisi operator pada saat beroperasirandom fatique dilakukan setiap hari pada waktu yang telah ditentukan oleh bidang safety dan tim medis yang ada di perusahaan. Kegiatan ini sangat penting untuk mencengah terjadi kecelakaan dalam bekerja.biasanya random fatique dilakukan pada \pm 10 orang setiap pengecekan. Dengan adanya kegiatan random fatique dapat mencegah terjadi kecelakaan akibat kelelahan yang dialami oleh operator. Menurut Setiawan et al. (2020), Analisis data tersebut menunjukkan driver mempunyai risiko tinggi terhadap kelelahan kerja sehingga upaya perusahaan melakukan fatique management yaitu melakukan cek kelelahan kerja.

\section{2). Kontroling Pengisian Kesiapan Kerja Harian (KKH)}

Menurut Potter \& Perry (2010) dalam Susanti et al. (2017) gangguan tidur dapat menimbulkan beberapa efek pada manusia. Ketika kurang tidur seseorang akan berpikir dan bekerja lebih lambat. Hal ini dapat mengakibatkan penurunan produktivitas kerja. Kualitas tidur buruk dapat mengakibatkan gangguan keseimbangan fisiologi dan psikologi. Dampak fisiologi meliputi penurunan aktivitas sehari-hari, rasa lelah, lemah dan daya tubuh menurun. Dampak psikologis meliputi depresi, stres, cemas dan tidak konsentrasi. Oleh karena itu, kontroling pada pengisian $\mathrm{KKH}$ sangat diperlukan untuk mengetahui jumlah jam tidur yang dilakukan oleh operator. Pada kegiatan ini diharapkan pengawas lebih teliti dalam melihat jam tidur karena dapat berpengaruh pada kinerja operator saat mengoperasikan unit. Kegiatan Kontroling KKH sangat dibutuhkan agar pengawas lapangan mengetahui jumah waktu tidur operator setelah bekerja, KKH ditandatangani oleh istri ataupun saudara. Jumlah waktu tidur kurang maka operator bisa tertidur saat mengemudikan alat.

\section{3). Kegiatan Kontroling Jalan}

Kegiatan Kontroling jalan dilakukan untuk mengetahui kondisi jalan yang ada pada tempat operasi. Kegiatan Kontroling jalan sangat diperlukan karena berpengaruh produksi perusahaan dan keselamatan operator. Kegiatan Kontroling jalan sangat penting dilakukan oleh dozer dan grader.Salah satu faktor utama yang mempengaruhi produksi penambangan batubara adalah 
sistem pengangkutan. Faktor yang mempengaruhi cycle time antara lain jarak angkut, kemiringan jalan, tahanan gulir, geometri jalan (lebar dan grade jalan, radius tikungan), faktor kesepadanan alat (match factor) (Toha, et al. 2019). Lokasi SM-B2 yang bergelombang ada pada jalan menuju disposal. Jika kondisi jalan terlalu bergelombang maka operator dapat mengalami sakit pinggang dan jika tanggul tidak standar (tinggi minimal setinggi ban HD) maka dapat berpotensi menyebabkan unit keluar dari jalan. Menurut Aldiyansah, et al. (2016), Kondisi jalan yang tidak sesuai dan cenderung dipaksakan akan mempengaruhi tidak nyamannya operator alat untuk melintasi jalan, produktivitas umur alat menurun, dan berpotensi menimbulkan kecelakaan.

4). Kegiatan Kontroling Debu

Kegiatan Kontroling debu sangat diperlukan agar jarak pandang antar unit tidak terganggu dengan adanya debu. Debu ini dapat menyebakan kecelakaan akibat jarak pandang yang terganggu. Pencegahan debu dapat dilakukan dengan penyiraman menggunakan water tank yang ada. Sebaiknya untuk penyiraman dilakukan \pm 10 Menit sebelum waktu istirahat dan sebelum pergantian change regu (Jika cuaca panas). Kegiatan kontrolling debu sangat dibutuhkan agar jarak pandang operator tidak terganngu, rendahnya jarak pandang mata dapat menimbulkan kecelakaan saat mengemudikan alat. Berdarsarkan Standard Operating Procedure (SOP) pada PT. Sims Jaya Kaltim.

\section{KESIMPULAN}

Berdasarkan penelitian yang telah dilaksanakan maka didapatkan kesimpulan sebagai berikut:

1). Berdasarkan dari hasil pengukuran beban mental yang telah dilakukan dapat diketahui geometri jalan dan debu berpengaruh terhadap beban mental yang dilalami operator. Penelitian beban kerja yang telah dilakukan dengan menggunakan NASA -TLX diapatkan hasil beban kerja mental secara keseluruhan sebesar 66.60 atau tergolong tinggi yang berarti harus dilakukan pemantauan terhadap operator HD Komatsu 785-7 saat melakukan pekerjaan.

2). Berdasarkan hasil pengukuran beban fisik yang telah dilakukan untuk operator dengan menggunakan metode \%CVL maka didapatan hasil sebesar $17.70 \%$ yang termasuk dalam kategori ringan yang berarti operator HD Komatsu 785-7 tidak mengalami beban kerja fisik saat melakukan pekerjaannya. Hal ini dikarenakan operator bekerja dalam posisi duduk sehingga energi yang dikeluarkan tidak terlalu besar.

3). Berdasarkan penelitian yang telah dilakukan didapatkan rekomendasi usulan perbaikan diantaranya kegiatan kontroling random fatique, kontroling pengisian $\mathrm{KKH}$, kegiatan kontroling jalan, dan kegiatan kontroling debu.

\section{UCAPAN TERIMA KASIH}

Saya sangat berterima kasih kepada pihak perusahaan yang telah mengizinkan saya untuk melakukan penelitian serta pembimbing selama melakukan penelitiaan dan kepada Ibu Lina Dianati Fatimahhayati, S.T., M.T. dan Bapak Willy Tambunan, S.T., M.T. selaku pembimbing saya yang selalu mengarahkan saya dalam penyusunan artikel ini.

\section{DAFTAR PUSTAKA}

Aldiyansyah, Husain, J. R., \& Nurwaskito, A. (2016), Analisis Geometri Jalan Di Tambang Utara Pada Pt. Ifishdeco Kecamatan Tinanggea Kabupaten Konawe Selatan Provinsi Sulawesi Tenggara. Jurnal Geomine, Vol. 4.

Amri, H. (2017). Analisis Beban Kerja Psikologis dengan Menggunakan Metode NASA-TLX pada Operator Departemen Fiber Line di PT. Toba Pulp Lestari. Industrial Engineering Journal, Vol. 6. 
Birana, A. I., Andy, A., \& Azwar, M. (2019). Kelelahan Kerja Operator Dump Truck (Studi Analitik PT. Indonesia Pratama, Tabang Kutai Kartanegara, Kalimantan Timur). Jurnal Kesehatan Masyarakat, Vol. 9.

Diniaty, D.,\& Ikhsan, M. (2018). Beban Kerja Mental Lantai Produksi Pabrik Kelapa Sawit dengan Metode NASA -TLX di PT. Bina Pratama Sakanto Jaya, Dharmasyara. Jurnal Tenik Industri, Vol. 4.

Farihah, T., \& Annisa, R. N. (2017). Analisis Beban Kerja Fisik Sebagai Dasar Penentuan Waktu Istirahat Yang Optimal. Intergrated Lab Journal, Vol. 5.

Purwaningsih, D., Rosyida, E. E., \& Bae, I. (2017). Analisis beban kerja fisik dan mental PT. Energi Agro Nusantara dengan metode Cardiovaskular Load (CVL) dan NASA-TLX. Seminar Nasional Teknik Industri 2017.

Puteri, R. M. A. \& Sukarna, Z. N. K. (2017). Analisis Beban Kerja Dengan Menggunakan Metode CVL dan NASA-TLX. Jurnal Spektrum Industri, Vol. 15.

Ramdan, I. M. (2006). Dasar-Dasar Kesehatan dan Keselamatan Kerja. Penerbit Up. Fakultas Kesehatan Masyarakat Universitas Mulawarman,Kalimantan Timur.

Setiawan, B., Fauzan, A., \& Norfai. (2020). Tingkat Kelelahan Kerja Pada Driver Dump Truck Ditinjau Dari Aspek Masa Kerja Dan Usia Di Pt Hasnur Riung Sinergi Site Pt Bhumi Rantau Energi Tahun 2019. MTPH Journal, Vol. 4.

Susanti, E., Kusuma, F. H.D., \& Rosdiana, Y. (2017). Hubungan Tingkat Stres Kerja Dengan Kualitas Tidur Pada Perawat Di Puskesmas Dau Malang. Nursing News, Vol. 23, No 3.

Toha, M. T., Nofanda, R., \& Busyaf, R., 2019, Analisis Efisiensi Kerja Dan Produktivitas Pengangkutan Batubara Sistem Shovel - Dump Truck. Jurnal Pertambangan, Vol. 3.

Wignjosoebroto, S. (1995). Ergonomi Studi Gerak dan Waktu. Guna Widya, Surabaya, Indonesia. 